\title{
Site and Mechanism of Action of Trichlormethiazide in Rabbit Distal Nephron Segments Perfused In Vitro
}

\author{
Toshikatsu Shimizu, ${ }^{\star \ddagger}$ Koji Yoshitomi, ${ }^{\star}$ Masuhisa Nakamura, ${ }^{\ddagger}$ and Masashi Imai ${ }^{\star}$ \\ *Department of Pharmacology, National Cardiovascular Center Research Institute, Osaka 565, \\ and ${ }^{\ddagger}$ Shionogi Research Laboratories, Shionogi \& Co., Ltd., Osaka 553, Japan
}

\begin{abstract}
To determine the exact site and mechanism of action of thiazide diuretics, effects of $10^{-4} \mathrm{M}$ trichlormethiazide (TCM) on $\mathrm{NaCl}$ transport were examined in the distal convoluted tubule (DCT), the connecting tubule (CNT) and the cortical collecting duct (CCD) of rabbit kidney by the in vitro microperfusion technique. TCM added to the lumen decreased lumen-to-bath ${ }^{36} \mathrm{Cl}$ flux $\left(\mathrm{J}_{\mathrm{Cl}(\mathrm{LB})}\right)$ only in the $\mathrm{CNT}$ without changing the transmural voltage $\left(V_{\mathrm{T}}\right)$. In the DCT, $10^{-4} \mathrm{M}$ furosemide did not change $J_{\mathrm{Cl(LB)}}$ even if it was added to the lumen with $10^{-4} \mathrm{M}$ TCM, whereas $10^{-5} \mathrm{M}$ amiloride in the lumen decreased the lumen-to-bath ${ }^{22} \mathrm{Na}$ flux $\left(\mathrm{J}_{\mathrm{Na}(\mathrm{LB})}\right)$ and $\mathrm{V}_{\mathrm{T}}$. In the CNT, TCM added to the lumen did not affect the bath-to-lumen ${ }^{36} \mathrm{Cl}$ flux. Addition of TCM to the bath slightly decreased $J_{C(L B)}$. Luminal addition of $10^{-4} \mathrm{M}$ TCM also decreased $J_{\mathrm{Na}(\mathrm{LB})}$. Amiloride at $10^{-5} \mathrm{M}$ in the lumen decreased both $J_{\mathrm{Na}(\mathrm{LB})}$ and $V_{\mathrm{T}}$. Addition of TCM with $10^{-5} \mathrm{M}$ amiloride further decreased $J_{\mathrm{Na}(\mathrm{LB})}$ without affecting $V_{\mathrm{T}}$, indicating that TCM affects the electroneutral $\mathrm{Na}^{+}$transport, which is distinct from the amiloride-sensitive conductive $\mathrm{Na}^{+}$pathway. When $\mathrm{Na}^{+}$was removed from the lumen, $J_{\mathrm{C}(\mathrm{CBB})}$ was markedly decreased, but addition of TCM did not cause further decrease in $J_{\mathrm{Cl}(\mathrm{LB})}$. Furosemide did not affect $J_{\mathrm{Cl}(\mathrm{LB})}$, but addition of both $10^{-4} \mathrm{M}$ TCM and furosemide decreased $J_{\mathrm{Cl}(L B)}$, indicating that $\mathrm{Na}^{+}-\mathrm{K}^{+}-2 \mathrm{Cl}^{-}$cotransport is not involved in the action of TCM. Removal of $\mathrm{HCO}_{3}^{-}$slightly decreased $J_{\mathrm{C}(\mathrm{LB})}$, and TCM caused further decrease in $J_{\mathrm{Cl}(\mathrm{LB})}$. Amiloride at $10^{-3} \mathrm{M}$, a concentration supposed to inhibit the $\mathrm{Na}^{+} / \mathrm{H}^{+}$antiport, slightly decreased $J_{\mathrm{C}(\mathrm{LB})}$, and addition of TCM caused a further marked decrease in $J_{\mathrm{Jl}(\mathrm{LB}) \text {. }}$ The similar results were also obtained when the combined effects of $10^{-3} \mathrm{M}$ 4,4'-diisothiocyano-stilben2,2'-disulfonate(DIDS) and $10^{-4} \mathrm{M}$ TCM were examined. These findings suggest that the parallel antiport of $\mathrm{Na}^{+} / \mathrm{H}^{+}$ and $\mathrm{Cl}^{-} / \mathrm{HCO}_{3}^{-}$is not involved in the action of TCM. By excluding other possible mechanisms involving neutral $\mathrm{Na}^{+}$-dependent $\mathrm{Cl}^{-}$transport, we conclude that TCM inhibits $\mathrm{Na}^{+}-\mathrm{Cl}^{-}$ cotransport in the luminal membrane of the rabbit CNT.
\end{abstract}

\section{Introduction}

Although thiazide diuretics have been widely used in the treatment of edema and hypertension for many years, the exact

Address reprint requests to Dr. Imai, Department of Pharmacology, National Cardiovascular Center, Research Institute, 5-7-1 Fujishirodai, Suita, Osaka 565, Japan.

Received for publication 27 October 1987 and in revised form 17 March 1988.

J. Clin. Invest.

(C) The American Society for Clinical Investigation, Inc.

$0021-9738 / 88 / 08 / 0721 / 10 \$ 2.00$

Volume 82, August 1988, 721-730 sites and mechanisms of action within the kidney are not definitely established. The observations that thiazide diuretics decreased free water clearance without affecting free water reabsorption provided indirect evidence that they act on the socalled cortical diluting segments $(1-3)$, which include the cortical thick ascending limb of Henle's loop as well as other distal nephron segments.

More direct evidence for distal nephron site of action of thiazides was provided by the in vivo micropuncture and microperfusion studies (4-10). However, it is well known that the distal convoluted tubule as defined by the micropuncture technique contains structurally as well as functionally distinct three nephron segments (11-14) including the distal convoluted tubule (DCT), ${ }^{1}$ the connecting tubule (CNT), and the cortical collecting duct (CCD). In vivo microperfusion studies in rat distal nephron $(8,10)$ demonstrated that thiazide diuretics act only on early portion of the distal nephron, suggesting that the distal convoluted tubule is the site of action of thiazide diuretics. In the rabbit, the transitions from one to the other segment along the distal nephron are abrupt (11), and therefore functions of a well defined segment can be examined by the in vitro microperfusion technique (13-17).

This study elucidates the site and mechanism of action of thiazide diuretics in well defined distal nephron segments. For this purpose, we examined effects of trichlormethiazide (TCM) on $\mathrm{NaCl}$ transport in the rabbit distal nephron segments by the in vitro microperfusion technique. We report that TCM inhibits $\mathrm{Na}^{+}-\mathrm{Cl}^{-}$cotransport by acting exclusively on the CNT, at least in the rabbit kidney.

\section{Methods}

In vitro microperfusion of isolated renal tubules. The technique of isolated renal tubular perfusion developed by Burg et al. (18) was employed as modified previously $(13,15)$. Male Japanese white rabbits, maintained on standard rabbit chow and tap water, were anesthetized with pentobarbital $(35 \mathrm{mg} / \mathrm{kg}$, i.v.) and kidneys were removed. Kidney slices 1-3 mm thickness were made and placed in a cooled dish containing an artificial solution simulating intracellular ion composition $\left(\mathrm{KCl} 14, \mathrm{~K}_{2} \mathrm{HPO}_{4}, 44, \mathrm{KH}_{2} \mathrm{PO}_{4} 14, \mathrm{NaHCO}_{3}\right.$ 9, sucrose $160 \mathrm{mM}$; $\mathrm{pH}$ 7.4). The composition was same as Collin's solution except that glucose was replaced by sucrose. This dissection medium was selected because it has been reported that intracellular fluid-like solutions are much better in preserving kidney tissue metabolically (19) as well as functionally $(20,21)$. We have also confirmed in preliminary studies that the function of rabbit proximal straight tubule was well preserved even after kidney slices were kept at $5^{\circ} \mathrm{C}$ for $24 \mathrm{~h}$.

Three different distal nephron segments, including the DCT, CNT,

1. Abbreviations used in this paper: $\mathrm{CCD}$, cortical collecting duct; CNT, connecting tubule; DCT, distal convoluted tubule; DIDS, 4,4'diisothiocyano-stilben-2,2'-disulfonate; $J_{\mathrm{Cl}(\mathrm{BL})}$, bath-to-lumen $\mathrm{Cl}^{-}$flux; $J_{\mathrm{CI}(\mathrm{LB})}$, lumen-to-bath Cl-flux; $J_{\mathrm{Na}(\mathrm{LB})}$, lumen-to-bath $\mathrm{Na}^{+}$flux; TCM trichlormethiazide; $V_{\mathrm{T}}$, transmural voltage. 
and $\mathrm{CCD}$, were isolated by identifying them according to the following criteria. The DCT was obtained from the superficial nephron. The segment was located in the vicinity of the superficial glomerulus, and was identified by its bright appearance. The CNT was obtained from the nephron arcade, and was identified by the existence of at least two branches and its granular appearance. The CCD was obtained from the medullary ray and was identified by its straight shape and light appearance. The validity of this criteria was confirmed in each instance by morphological appearance of epithelia observed on an inverted microscope during perfusion of the tubules. Detailed morphological descriptions and photographs of these segments have been reported previously (13).

The isolated tubules were transferred to a temperature controlled bath and were perfused at $37^{\circ} \mathrm{C}$. The compositions of artificial solutions used in this study are shown in Table I. Bicarbonate Krebs Ringer (BKR) solution was the main perfusion medium. In some experiments, the sodium in the lumen was replaced with choline, or the bicarbonate in the bath and perfusate was replaced with Hepes-gluconate (Table I). Bicarbonate-containing solution was bubbled with 95\% $\mathrm{O}_{2}-5 \% \mathrm{CO}_{2}$ to attain a $\mathrm{pH}$ of 7.4. Bicarbonate-free solution was bubbled with $100 \% \mathrm{O}_{2}$.

The electrical circuit to measure the transmural voltage $\left(V_{\mathrm{T}}\right)$ was identical to that previously reported (13). A calomẹl half-cell electrode was connected by an agar bridge to the perfusion pipette. Another electrode was connected by an agar bridge to the bath. The electrical potential difference between the two electrodes was measured with an electrometer (Keithely 602, Keithely Instruments, Inc., Cleveland, $\mathrm{OH})$. It has been reported that the $V_{\mathrm{T}}$ of the CNT and DCT were always negative in the lumen and were pressure-dependent $(13,22)$. In the CNT, when the perfusion pressure was varied from 2 to $40 \mathrm{~cm}$ $\mathrm{H}_{2} \mathrm{O}$, the $V_{\mathrm{T}}$ decreased as a function of the height of reservoir from about -20 to $-2 \mathrm{mV}$. Therefore, this study was performed at a fixed height of the fluid reservoir connected to the perfusion pipette of $\sim 10$ $\mathrm{cm} \mathrm{H}_{2} \mathrm{O}$. Under these experimental conditions, the perfusion rate and

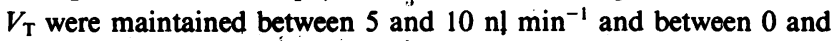
$-10 \mathrm{mV}$, respectively.

Unidirectional fluxes of ${ }^{36} \mathrm{Cl}$ or ${ }^{22} \mathrm{Na}$ from lumen to bath $\left(J_{\mathrm{Cl}(\mathrm{LB})}\right.$ or $\left.J_{\mathrm{Na}(\mathrm{LB})}\right)$ were meaşured by adding $3 \mu \mathrm{Ci} / \mathrm{ml}^{36} \mathrm{Cl}$ or $10 \mu \mathrm{Ci} / \mathrm{ml}^{22} \mathrm{Na}$ to the perfusate. The CCD is virtually impermeable to water in the absence of vasopressin, and both DCT and CNT are impermeable to water even in the presence of vasopressin $(13,22)$. Therefore, $J_{\mathrm{CI}(\mathrm{LB})}$ or $J_{\mathrm{Na}(\mathrm{LB})}$ can be calculated using the equation; $J_{\mathrm{C}(\mathrm{LB})}=\left(V_{0}[C]_{\mathrm{i}} / L\right)$ $\left(1-\left[C^{*}\right]_{0} /\left[C^{*}\right]_{i}\right)$, where $[C]_{i}$ is the concentration of solute in the perfusate, $V_{0}$ is the collection rate, $L$ is the tubular length, and $\left[C^{*}\right]_{\mathrm{i}}$ and $\left[C^{*}\right]_{0}$ are concentrations of isotope in the perfusate and the collected fluid, respectively. The lumen-to-bath flux coefficient of $\mathrm{Cl}^{-}$

Table I. Composition of Perfusing and Bathing Solutions

\begin{tabular}{lccc}
\hline \multicolumn{1}{c}{ Solution } & BKR & $\mathrm{Na}^{+}$-free & Bicarbonate-free \\
\hline $\mathrm{Na}^{+}$ & 140.5 & - & 140.5 \\
$\mathrm{~K}^{+}$ & 5.0 & 5.0 & 5.0 \\
$\mathrm{Ca}^{2+}$ & 1.8 & 1.8 & 1.8 \\
$\mathrm{Mg}^{2+}$ & 1.0 & 1.0 & 1.0 \\
$\mathrm{Choline}^{2}$ & - & 138.3 & - \\
$\mathrm{Cl}^{-}$ & 120.6 & 120.6 & 120.6 \\
$\mathrm{HCO}_{3}^{-}$ & 25.0 & 25.0 & - \\
$\mathrm{HPO}_{4}^{2-} / \mathrm{H}_{2} \mathrm{PO}_{4}^{-}$ & 1.0 & 1.0 & 1.0 \\
Gluconate & - & - & 15.0 \\
Hepes & - & - & 10.0 \\
& & & \\
\hline
\end{tabular}

Concentrations are shown in $\mathrm{mM}$. All solutions contain in $\mathrm{mM}$ : Dglucose 3.8, L-alanine 5.0, citrate 1.5, and glutamate 3.5. BKR, bicarbonate Krebs-Ringer.
$\left(K_{\mathrm{CK}(\mathrm{LB})}\right)$ or $\mathrm{Na}^{+}\left(K_{\mathrm{Na}(\mathrm{LB})}\right)$ was calculated as follows (23): $K_{(\mathrm{LB})}=\left(V_{0} / L\right)$ $\ln \left(\left[C^{*}\right]_{\mathrm{i}} /\left[C^{*}\right]_{0}\right)$. The bath-to-lumen flux coefficient $\left(K_{\mathrm{C}(\mathrm{BL})}\right)$ and the influx of ${ }^{36} \mathrm{Cl}$ from bath to lumen $\left(J_{\mathrm{Cl}(\mathrm{BL})}\right)$ were calculated as (24); $K_{\mathrm{Cl}(\mathrm{BL})}=\left(V_{0} / L\right) \ln \left\{\left[C^{*}\right]_{\mathrm{b}} /\left(\left[C^{*}\right]_{\mathrm{b}}-\left[C^{*}\right]_{0}\right)\right\}$ and $J_{\mathrm{C}(\mathrm{BL})}=[C l]_{\mathrm{b}} K_{\mathrm{Cl}(\mathrm{BL})}$, where $[\mathrm{Cl}]_{\mathrm{b}}$ is the concentration of $\mathrm{Cl}^{-}$in the bath. $\left[C^{*}\right]_{0}$ and $\left[C^{*}\right]_{\mathrm{b}}$ are the concentrations of ${ }^{36} \mathrm{Cl}$ in the collected fluid and the bath, respectively.

Net $\mathrm{Cl}^{-}$flux $\left(\mathrm{J}_{\mathrm{Cl}(\text { net) }}\right)$ was measured by adding ${ }^{36} \mathrm{Cl}$ both to the perfusate and the bathing fluid at same concentration. $\mathrm{J}_{\mathrm{C}(\text { net) }}$ was calculated as; $J_{\mathrm{Cl}(\text { net) }}=\left(V_{0}[C l]_{\mathrm{i}} / L\right)\left(1-\left[C^{*}\right]_{0} /\left[C^{*}\right]_{\mathrm{i}}\right)$, where $[C l]_{\mathrm{i}}$ is $\mathrm{Cl}^{-}$ concentration in the perfusate, $V_{0}$ is the collection rate, $L$ is the tubular length, $\left[C^{*}\right]_{0}$ and $\left[C^{*}\right]_{i}$ are concentration of ${ }^{36} \mathrm{Cl}$ in the collected fluid and perfusate, respectively.

Usually, we used data of unidirectional fluxes to represent transport parameters, but we also gave flux coefficients in tables for convenience of comparison of fluxes normalized by ion concentration.

The radioactivity of ${ }^{36} \mathrm{Cl}$ was measured with a liquid scintillation counter (LKB Wallac, 1217 Rack Beta; LKB Instruments, Gaithersburg, MD). Radioactivity of ${ }^{22} \mathrm{Na}$ was measured with a gamma counter (LKB Wallac, 1282 Compu Gamma).

Statistical analysis. The mean value for three collection periods was used as a representative value for a given experimental condition. Data were expressed as means \pm SE. Statistical analysis was performed by either the paired or nonpaired $t$ test, when appropriate.

Chemicals. TCM (Shionogi Co. Ltd., Osaka, Japan) was obtained as pure compound and dissolved in dimethylsulfoxide (DMSO) immediately before use. The original solutions were diluted at least 100 -fold with an artificial solution used for the perfusion experiments to obtain the final concentration of $10^{-4} \mathrm{M}$. In preliminary studies we confirmed that this amount of DMSO had no effect on net volume flux, lumento-bath $\mathrm{Cl}^{-}$flux and $\mathrm{V}_{\mathrm{T}}$ in all segments used in this study (Table II). Amiloride and furosemide were purchased from Sigma Chemical Co., (St. Louis, MO) and Hoechst Japan (Tokyo), respectively, 4,4'-diisothiocyano-stilben-2,2'-disulfonate (DIDS) was obtained from Funakoshi Chemical Co. (Tokyo). ${ }^{22} \mathrm{Na}$ and ${ }^{36} \mathrm{Cl}$ were products of New England Nuclear (Boston, MA) and Amersham International (Buckinghamshire, UK), respectively.

\section{Results}

Site of action of TCM in the distal nephron segments. To clarify the site of action of TCM in the distal nephron segments, we observed the effect of TCM on the lumen-to-bath $\mathrm{Cl}^{-}$flux in the DCT, CNT and CCD. The results are summarized in Table III and individual data are depicted in Fig. 1. When $10^{-4}$ $\mathrm{M}$ TCM was added to the lumen, $\mathrm{Cl}^{-}$flux was reduced only in the CNT but not in the DCT and CCD. In the CNT, $J_{\mathrm{CI}(\mathrm{LB})}$ was decreased from 914 to $657 \mathrm{pmol} \mathrm{mm} \mathrm{min}^{-1}$ and $K_{\mathrm{Cl}(\mathrm{LB})}$ from 17.12 to $11.25 \times 10^{-7} \mathrm{~cm}^{2} \mathrm{~s}^{-1}$ without significant change in $V_{\mathrm{T}}$. Thus the CNT is the target of the action of TCM. Since the data obtained by in vivo microperfusion studies in rats $(8,10)$ strongly suggest that the DCT is the site of action of thiazide diuretics, we have carefully conducted 2 additional protocols to characterize the segments of DCT more specifically. In the first protocol, we observed effects of furosemide and TCM on the lumen-to-bath $\mathrm{Cl}^{-}$flux in the DCT. The results are summarized in Fig. 2. Administration of $10^{-4} \mathrm{M}$ furosemide in the lumen did not affect the $\mathrm{Cl}^{-}$flux or the transmural voltage. Addition of $\mathrm{TCM} 10^{-4} \mathrm{M}$ to the lumen in combination with furosemide did not change these parameters as well. These observations indicate that the segment defined as the DCT is clearly distinct from the thick ascending limb, which is supposed to display lumen positive voltage and where $\mathrm{Cl}^{-}$transport is inhibited by furosemide. In this series of experiments, we confirmed again that TCM was without effect on $\mathrm{Cl}^{-}$flux in the DCT. 
Table II. Effect of $1 \%$ Dimethylsulfoxide on Net Water Flux $\left(J_{v}\right), J_{C I(L B)}$, and $V_{T}$ in the DCT, CNT, and CCD

\begin{tabular}{ccccccc}
\hline Segments & $(n)$ & DMSO & $V_{0}$ & $J_{\mathrm{v}}$ & $J_{\text {CKLB }}$ & $V_{\mathrm{T}}$ \\
\hline & & $\%$ & $n l \mathrm{~min}^{-1}$ & $n l \mathrm{~mm}^{-1} \mathrm{~min}^{-1}$ & $p m m^{-1} \mathrm{~min}^{-1}$ & $-3.9 \pm 1.5$ \\
DCT & $(4)$ & 0 & $8.73 \pm 0.77$ & $-0.04 \pm 0.05$ & $444 \pm 62$ & $-4.0 \pm 1.6$ \\
& & 1 & $7.97 \pm 0.69$ & $0.04 \pm 0.18$ & $404 \pm 12$ & $-8.1 \pm 1.1$ \\
CNT & $(5)$ & 0 & $8.61 \pm 0.79$ & $-0.03 \pm 0.12$ & $614 \pm 49$ & $-8.2 \pm 1.0$ \\
& & 1 & $8.37 \pm 0.55$ & $0.06 \pm 0.08$ & $661 \pm 118$ & $-6.7 \pm 2.3$ \\
CCD & $(5)$ & 0 & $8.63 \pm 0.54$ & $0.07 \pm 0.09$ & $252 \pm 51$ & $-6.8 \pm 2.2$ \\
& & 1 & $9.04 \pm 0.65$ & $0.08 \pm 0.04$ & $242 \pm 42$ & \\
\hline
\end{tabular}

$n=$ number of tubules.

Gross et al. (22) have reported that administration of amiloride to the lumen of the rabbit DCT suppressed the lumen negative $V_{\mathrm{T}}$. Therefore, in the second protocol, we intended to confirm and extend their observation by examining effects of amiloride on the lumen-to-bath $\mathrm{Na}^{+}$flux. As summarized in Fig. 3, $10^{-5} \mathrm{M}$ amiloride added to the lumen decreased the $V_{T}$ as well as $\mathrm{Na}^{+}$flux. These effects were reversible.

All the following studies are confined to the CNT. Seven separate experiments were conducted to examine the effect of luminal application of TCM on the bath-to-lumen $\mathrm{Cl}^{-}$flux (Table IV). The results show that TCM did not affect the bath-to-lumen $\mathrm{Cl}^{-}$flux. However, it is difficult to estimate the net $\mathrm{Cl}^{-}$flux across the CNT by comparing with the data shown in Table III, since bidirectional $\mathrm{Cl}^{-}$fluxes were not measured in the same tubule. Because of large scatter of the data, we are not allowed to compare the unpaired samples without doing a large scale of experiments. In order to examine whether TCM decreases net $\mathrm{Cl}^{-}$flux, we measured net $\mathrm{Cl}^{-}$flux under the condition where ${ }^{36} \mathrm{Cl}$ concentration of the perfusing fluid was identical to that in the bathing fluid. The results are summarized in Table V. It is clear that TCM decreases net $\mathrm{Cl}^{-}$flux in the CNT.

In order to examine whether the luminal application is the major route of diuretic action, we observed the effect of TCM added to the bath and or lumen on $J_{\mathrm{Cl}(\mathrm{LB})}$. After the control period, $10^{-4} \mathrm{M} \mathrm{TCM}$ was added at first to the bath, and then the drug was added to the lumen with the drug concentration in the bath being kept constant. In the last period, the drug was eliminated only from the lumen. The results are summarized in Fig. 4. When TCM was added to the bath a small but significant decrease in $J_{\mathrm{Cl}(\mathrm{LB})}$ was observed. However, addition of $10^{-4} \mathrm{M} \mathrm{TCM}$ to the lumen in the presence of the drug in the bath caused a much greater reduction of $J_{\mathrm{C}(\mathrm{LB})}$ from 818 to 551 pmol $\mathrm{mm}^{-1} \mathrm{~min}^{-1}$.

Effect on $\mathrm{Na}^{+}$flux. To examine whether the inhibition of $\mathrm{Cl}^{-}$transport by TCM is associated with an inhibition of $\mathrm{Na}^{+}$ transport, we observed effect of $10^{-4} \mathrm{M} \mathrm{TCM}$ in the lumen on the lumen-to-bath ${ }^{22} \mathrm{Na}$ flux. The results are summarized in Table VI. The lumen-to-earth ${ }^{22} \mathrm{Na}$ flux in the control period was lower than the value for $\mathrm{Cl}^{-}$. Administration of $10^{-4} \mathrm{M}$ TCM to the lumen caused a marked decrease in $J_{\mathrm{Na}(\mathrm{LB})}$ from 523 to $354 \mathrm{pmol} \mathrm{mm} \mathrm{mm}^{-1} \mathrm{~min}^{-1}$. This effect of TCM was reversible. These data indicate that TCM inhibits $\mathrm{Na}^{+}$flux as well as $\mathrm{Cl}^{-}$flux.

Since TCM inhibited $\mathrm{NaCl}$ transport in the CNT without affecting $\mathrm{V}_{\mathrm{T}}$, it is unlikely that the drug influences rheogenic transport processes. To confirm this issue, we examined whether TCM inhibits only the $\mathrm{Na}^{+}$flux which is independent

Table III. Effect of $10^{-4} \mathrm{M}$ TCM in the Lumen on $\mathrm{Cl}^{-}$Transport in the Distal Nephron Segments

\begin{tabular}{|c|c|c|c|c|c|}
\hline Period & Lumen TCM & $V_{0}$ & $K_{\mathrm{CQLB}}$ & $J_{\text {CQLB) }}$ & $T_{\mathrm{v}}$ \\
\hline & $M$ & nl/min & $10^{-7} \mathrm{~cm}^{2} \mathrm{~s}^{-1}$ & 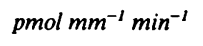 & $m V$ \\
\hline \multicolumn{6}{|c|}{$D C T(n=7, \mathrm{~L}=0.42 \pm 0.05 \mathrm{~mm})$} \\
\hline $\mathrm{C}$ & 0 & $5.75 \pm 0.37$ & $9.04 \pm 1.16$ & $528 \pm 88$ & $-6.8 \pm 1.7$ \\
\hline $\mathbf{E}$ & $10^{-4}$ & $5.18 \pm 0.15$ & $8.47 \pm 1.67$ & $510 \pm 92$ & $-6.6 \pm 1.9$ \\
\hline $\mathbf{R}$ & 0 & $5.23 \pm 0.29$ & $8.81 \pm 1.77$ & $534 \pm 94$ & $-5.6 \pm 1.6$ \\
\hline \multicolumn{6}{|c|}{$C N T(n=8, \mathrm{~L}=0.34 \pm 0.05 \mathrm{~mm})$} \\
\hline $\mathrm{C}$ & 0 & $5.04 \pm 0.25$ & $17.12 \pm 2.54$ & $914 \pm 123$ & $-4.8 \pm 1.4$ \\
\hline $\mathrm{E}$ & $10^{-4}$ & $5.73 \pm 0.58$ & $11.25 \pm 1.75^{*}$ & $657 \pm 94^{*}$ & $-4.6 \pm 1.6$ \\
\hline $\mathbf{R}$ & 0 & $5.74 \pm 0.73$ & $13.93 \pm 2.16^{*}$ & $765 \pm 127^{*}$ & $-4.8 \pm 1.5$ \\
\hline \multicolumn{6}{|c|}{$C C D(n=4, \mathrm{~L}=0.77 \pm 0.05 \mathrm{~mm})$} \\
\hline $\mathrm{C}$ & 0 & $7.17 \pm 0.92$ & $12.52 \pm 2.12$ & $627 \pm 105$ & $-4.3 \pm 1.7$ \\
\hline $\mathrm{E}$ & $10^{-4}$ & $7.50 \pm 0.29$ & $11.54 \pm 2.54$ & $604 \pm 113$ & $-4.4 \pm 1.6$ \\
\hline $\mathbf{R}$ & 0 & $7.61 \pm 0.51$ & $10.63 \pm 2.19$ & $563 \pm 100$ & $-3.8 \pm 1.3$ \\
\hline
\end{tabular}

Abbreviations used in this table: $\mathrm{C}$, control period; $\mathrm{E}$, experimental period; $\mathrm{R}$, recovery period. $K_{\mathrm{CI}(\mathrm{LB})}$, lumen-to-bath flux coefficient for $\mathrm{Cl}^{-}$; $\mathrm{L}$, tubular length; $V_{0}$, perfusion rate; ${ }^{*} P<0.01$. 


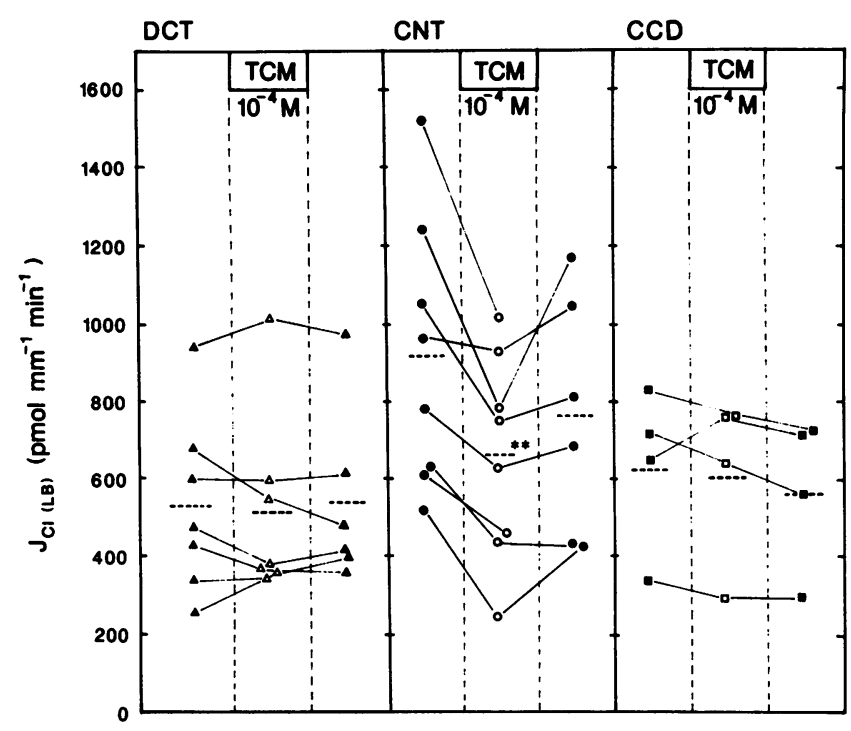

Figure 1. Effects of TCM on $\mathrm{J}_{\mathrm{Cl}(\mathrm{LB})}$ in distal nephron segments. Trichlormethiazide was added to the lumen. ${ }^{*} P<0.01$ as compared to the preceding values.
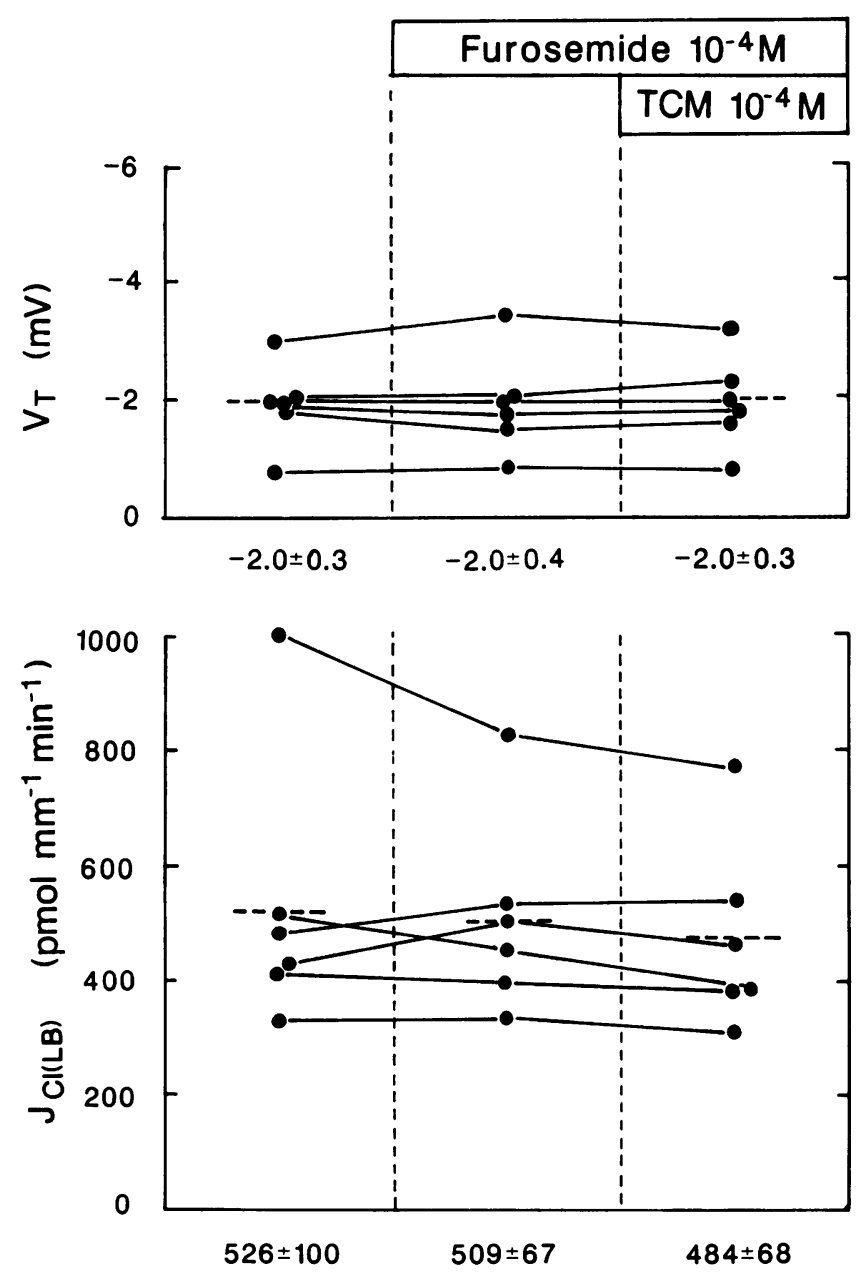

Figure 2. Effects of $10^{-4} \mathrm{M}$ furosemide and $10^{-4} \mathrm{M}$ TCM on $V_{\mathrm{T}}$ and $J_{\mathrm{C}(\mathrm{LB})}$ in the DCT. Tubular length was $0.38 \pm 0.03 \mathrm{~mm}$. Perfusion rates for each period were $8.24 \pm 1.69,7.92 \pm 1.15$, and $7.48 \pm 1.11 \mathrm{nl} /$ min, respectively.
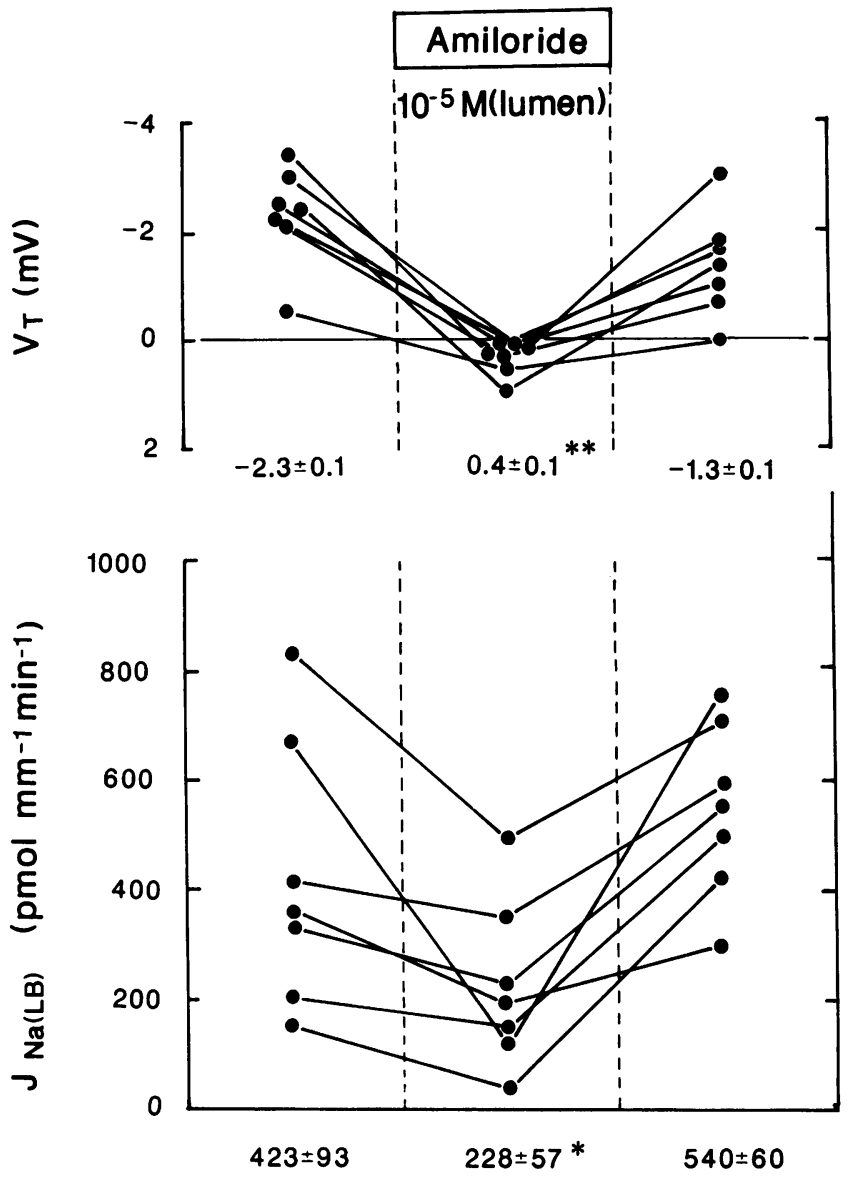

Figure 3. Effects of $10^{-5} \mathrm{M}$ amiloride in the lumen on $\mathrm{V}_{\mathrm{T}}$ and lumen-to-bath $\mathrm{Cl}^{-}$flux $J_{\mathrm{CI}(\mathrm{LB})}$ in the DCT. Values are means $\pm \mathrm{SE}$. Tubular length was $0.41 \pm 0.02$. ${ }^{* *} P<0.01,{ }^{*} P<0.05$ as compared to the preceding values.

of the amiloride sensitive component. After the control period, $10^{-5} \mathrm{M}$ amiloride was added to the lumen. In the next period, $10^{-4} \mathrm{M}$ TCM was added to the lumen in the presence of $10^{-5}$ $M$ amiloride. In the final period, recovery from the effects of these drugs was observed. The results of this protocol are summarized in Fig. 5. Amiloride added to the lumen at $10^{-5} \mathrm{M}$ inhibited $\mathrm{Na}^{+}$flux from 649 to $426 \mathrm{pmol} \mathrm{mm} \mathrm{mm}^{-1} \mathrm{~min}^{-1}$ in association with a significant reduction in $V_{\mathrm{T}}$ from -2.0 to $-0.1 \mathrm{mV}$. Under this circumstance, administration of $10^{-4} \mathrm{M}$ TCM in the lumen further decreased the $\mathrm{Na}^{+}$flux to $364 \mathrm{pmol}$ $\mathrm{mm}^{-1} \mathrm{~min}^{-1}$ without causing changes in $V_{\mathrm{T}}$. The parameter tended to recover when the drugs were eliminated from the lumen. These observations clearly indicate that there is an

Table IV. Effect of $10^{-4} M$ TCM in the Lumen on Bathto-Lumen ${ }^{36} \mathrm{Cl}$-flux in the CNT

\begin{tabular}{lcccc}
\hline \multicolumn{1}{c}{ Period } & $V_{0}$ & $K_{\mathrm{CUBL}}$ & $J_{\mathrm{C}(\mathrm{BL})}$ & $V_{\mathrm{T}}$ \\
\hline & $n l \mathrm{~min}^{-1}$ & $10^{-7} \mathrm{~cm}^{2} \mathrm{~s}^{-1}$ & $p m o l \mathrm{~mm}^{-1} \mathrm{~min}^{-1}$ & $\mathrm{mV}$ \\
Control & $9.77 \pm 0.55$ & $11.92 \pm 1.37$ & $862 \pm 99$ & $-3.7 \pm 0.8$ \\
TCM $10^{-4}$ & $9.05 \pm 0.14$ & $12.50 \pm 1.36$ & $904 \pm 99$ & $-3.5 \pm 0.9$
\end{tabular}

Data are from seven tubules with length of $0.39 \pm 0.02 \mathrm{~mm} . K_{\mathrm{C}(\mathrm{BL})}$, bath-to-lumen flux coefficient for $\mathrm{Cl}^{-}$. 
Table $V$. Effect of $10^{-4} M T C M$ in the Lumen on $\mathrm{Net} \mathrm{Cl}^{-}$Flux in the $\mathrm{CNT}$

\begin{tabular}{ccccc}
\hline Period & TCM (lumen) & $V_{0}$ & $J_{\text {CUnet) }}$ & \multicolumn{1}{c}{$V_{\mathrm{T}}$} \\
\hline & & $n l / \mathrm{min}$ & $p m o l ~ \mathrm{~mm}^{-1} \mathrm{~min}^{-1}$ & $\mathrm{mV}$ \\
$\mathrm{C}$ & 0 & $9.50 \pm 0.69$ & $405 \pm 55$ & $-2.2 \pm 0.5$ \\
$\mathrm{E}$ & $10^{-4} \mathrm{M}$ & $8.83 \pm 0.66$ & $281 \pm 59^{*}$ & $-2.1 \pm 0.5$ \\
E-C & & $0.67 \pm 0.04$ & $\Delta-124 \pm 48^{*}$ & $\Delta+0.1 \pm 0.2$
\end{tabular}

Data are from seven tubules with length of $0.38 \pm 0.03 \mathrm{~mm}$. Net $\mathrm{Cl}^{-}$ flux, $J_{\mathrm{Cl}(\text { net) }}$, was measured by adding ${ }^{36} \mathrm{Cl}$ to both perfusing and bathing fluid at the same concentration.

$* P<0.05$.

amiloride-sensitive $\mathrm{Na}^{+}$transport process in the CNT but that TCM inhibits the $\mathrm{Na}^{+}$flux, which is independent of amiloride action.
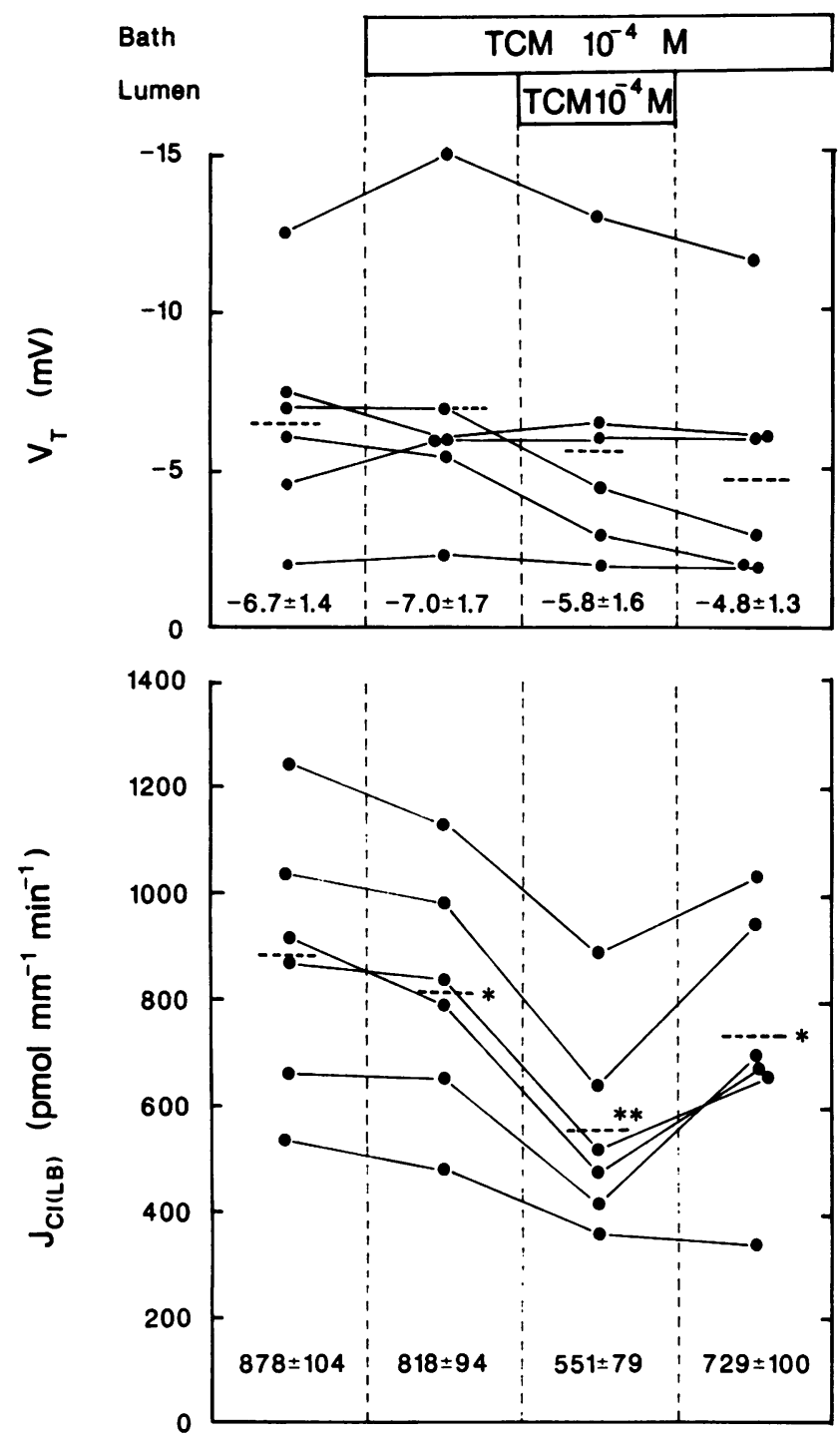

Figure 4. Examination of sidedness of the action of TCM in the CNT. Values are means \pm SE. Tubular length was $0.37 \pm 0.05 \mathrm{~mm}$. Perfusion rates in four periods were $6.28 \pm 0.39,6.15 \pm 0.36$, $5.74 \pm 0.30$, and $6.29 \pm 0.24 \mathrm{nl} / \mathrm{min}$, respectively. ${ }^{*} P<0.05,{ }^{* *} P$ $<0.01$ as compared to the preceding values.
Table VI. Effect of $10^{-4}$ M TCM in the Lumen on $\mathrm{Na}^{+}$Transport in the $\mathrm{CNT}$

\begin{tabular}{cccccc}
\hline Period & $\begin{array}{c}\text { Lumen } \\
\text { TCM }\end{array}$ & $V_{0}$ & $K_{\text {Na(18) }}$ & $J_{\text {Na(B) }}$ & $V_{\mathrm{T}}$ \\
\hline & $M$ & $n l \mathrm{~min}^{-1}$ & $10^{-7} \mathrm{~cm}^{2} \mathrm{~s}^{-1}$ & $p m o l m^{-1} \mathrm{~min}^{-1}$ & $\mathrm{mV}$ \\
$\mathrm{C}$ & 0 & $8.24 \pm 0.50$ & $6.84 \pm 0.65$ & $523 \pm 49$ & $-1.9 \pm 0.9$ \\
$\mathrm{E}$ & $10^{-4}$ & $8.23 \pm 0.59$ & $4.47 \pm 0.54^{*}$ & $354 \pm 42^{*}$ & $-2.0 \pm 0.1$ \\
$\mathrm{R}$ & 0 & $7.85 \pm 0.56$ & $6.64 \pm 0.63^{*}$ & $504 \pm 47^{*}$ & $-2.1 \pm 0.8$
\end{tabular}

Data are from eight tubules length of $0.39 \pm 0.03 \mathrm{~mm} . K_{\mathrm{Na}(\mathrm{LB})}$, lumento-bath flux coefficient for $\mathrm{Na}^{+} ;{ }^{*} P<0.01$ as compared to the values in the preceding periods.

$\mathrm{Na}^{+}$dependence of $\mathrm{Cl}$ flux. Since TCM inhibited both $\mathrm{Na}^{+}$ and $\mathrm{Cl}^{-}$fluxes without affecting $V_{\mathrm{T}}$, it is highly possible that TCM affects $\mathrm{Na}^{+}$dependent $\mathrm{Cl}^{-}$transport mechanisms including $\mathrm{Na}^{+}-\mathrm{Cl}^{-}$cotransport, $\mathrm{Na}^{+}-\mathrm{K}^{+}-2 \mathrm{Cl}^{-}$cotransport, and $\left(\mathrm{Na}^{+} / \mathrm{H}^{+}\right)-\left(\mathrm{Cl}^{-} / \mathrm{HCO}_{3}^{-}\right)$double antiport. Therefore, we first examined whether there are $\mathrm{Na}^{+}$-dependent $\mathrm{Cl}^{-}$transport processes in the luminal membrane of the CNT by observing the effect of elimination of $\mathrm{Na}^{+}$from the lumen on the lumen-tobath $\mathrm{Cl}^{-}$flux. After the control period, $\mathrm{Na}^{+}$was eliminated

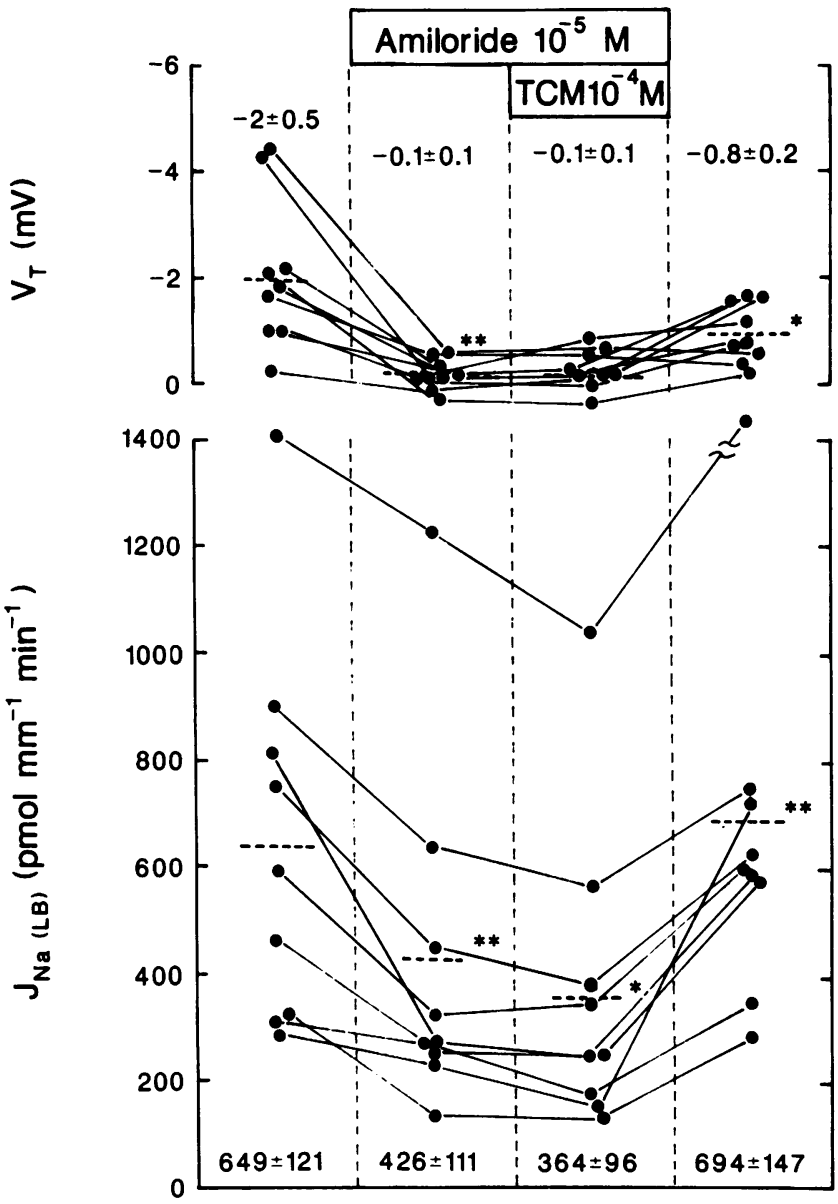

Figure 5. Effects of $10^{-5} \mathrm{M}$ amiloride and $10^{-4} \mathrm{M}$ TCM on $V_{\mathrm{T}}$ and $J_{\mathrm{Na}(\mathrm{LB})}$ in the CNT. Values are mean \pm SE. Tubular length was $0.42 \pm 0.05 \mathrm{~mm}$. Perfusion rates in four periods were $8.46 \pm 0.54$, $8.10 \pm 0.40,8.03 \pm 0.53$, and $8.78 \pm 0.45 \mathrm{nl} / \mathrm{min}$, respectively. ${ }^{*} P$ $<0.05,{ }^{* *} P<0.01$ as compared to the preceding values. 
from the lumen. In the next period, $10^{-4} \mathrm{M}$ TCM was added to the lumen in the absence of $\mathrm{Na}^{+}$. In the final period, the recovery from these maneuvers was observed. The results are summarized in Table VII. The elimination of $\mathrm{Na}^{+}$from the lumen decreased $J_{\mathrm{Cl}(\mathrm{LB})}$ from 964 to $706 \mathrm{pmol} \mathrm{mm} \mathrm{min}^{-1}$. In the absence of $\mathrm{Na}^{+}$in the lumen, addition of $10^{-4} \mathrm{M} \mathrm{TCM}$ to the lumen did not cause any significant reduction in $J_{\mathrm{Cl}(\mathrm{LB})}$. These observations indicate that there is a $\mathrm{Na}^{+}$-dependent $\mathrm{Cl}^{-}$transport system and that sodium is essential for inhibitory effect of TCM on chloride flux.

Effect of furosemide. In order to examine whether $\mathrm{Na}^{+}-\mathrm{K}^{+}-2 \mathrm{Cl}^{-}$cotransport contributes as a target of TCM action, we examined the effect of furosemide on $\mathrm{Cl}^{-}$flux across the CNT. The results are summarized in Fig. 6. Addition of $10^{-4} \mathrm{M}$ furosemide to the lumen did not change $J_{\mathrm{Cl}(\mathrm{LB})}$ as well as $V_{\mathrm{T}}$. When $10^{-4} \mathrm{M} \mathrm{TCM}$ was added to the lumen in the presence of furosemide, $J_{\mathrm{Cl}(\mathrm{LB})}$ decreased from 1111 to 569 pmol mm $\mathrm{mm}^{-1} \mathrm{~min}^{-1}$ without any change in $V_{\mathrm{T}}$. Since this concentration of furosemide is known to suppress $\mathrm{Na}^{+}-\mathrm{K}^{+}-2 \mathrm{Cl}^{-}$ cotransport in the thick ascending limb of Henle's loop, these observations may indicate that there is no such transport system in the CNT and that the target of TCM action is a $\mathrm{Na}^{+}$dependent $\mathrm{Cl}^{-}$transport system other than this triple cotransport.

Effect on parallel antiport of $\mathrm{Na}^{+} / \mathrm{H}^{+}$and $\mathrm{Cl} / \mathrm{HCO}_{3}^{-}$. It has been reported in various epithelia that the parallel antiport of $\mathrm{Na}^{+} / \mathrm{H}^{+}$and $\mathrm{Cl}^{-} / \mathrm{HCO}_{3}^{-}$is one of the mechanisms which represent apparent $\mathrm{Na}^{+}$-dependent $\mathrm{Cl}^{-}$transport. In order to examine whether the bicarbonate-dependent $\mathrm{Cl}^{-}$transport, if exists in the CNT, is the major component of the inhibitory effect of TCM, we observed effect of $\mathrm{HCO}_{3}^{-}$elimination on $\mathrm{Cl}^{-}$flux in the presence or absence of TCM. The results are summarized in Fig. 7. When $\mathrm{HCO}_{3}^{-}$was eliminated from the entire system, $J_{\mathrm{Cl}(\mathrm{LB})}$ decreased from 705 to $569 \mathrm{pmol} \mathrm{mm}^{-1} \mathrm{~min}^{-1}$. In the absence of $\mathrm{HCO}_{3}^{-}$, addition of $10^{-4} \mathrm{M}$ TCM further decreased $J_{\mathrm{Cl}(\mathrm{LB})}$ to $461 \mathrm{pmol} \mathrm{mm}^{-1} \mathrm{~min}^{-1}$, indicating that the inhibitory effect of TCM was additive to the effect of bicarbonate elimination.

To examine whether the parallel antiport system is independent of TCM-inhibitable $\mathrm{Cl}^{-}$flux, we observed the effect of DIDS on $J_{\mathrm{CI}(\mathrm{LB})}$ in the presence or absence of TCM. The data shown in Fig. 8 revealed that $10^{-3} \mathrm{M}$ DIDS added to the lumen slightly decreased $J_{\mathrm{CI}(\mathrm{LB})}$ and that addition of $10^{-4} \mathrm{M} \mathrm{TCM}$ with $10^{-3}$ DIDS further caused a large decrease in $J_{\mathrm{Cl}(\mathrm{LB})}$. This would indicate that the TCM-inhibitable $\mathrm{Cl}^{-}$flux is distinct from the DIDS-inhibitable component.

Table VII. Effect of $10^{-4} \mathrm{M}$ TCM in the Lumen on $\mathrm{Cl}^{-}$ Transport in the CNT under $\mathrm{Na}^{+}$-free Conditions

\begin{tabular}{|c|c|c|c|c|}
\hline Period & Lumen & $V_{0}$ & $K_{\mathrm{C}(\mathrm{LB})}$ & $J_{\text {CYLB) }}$ \\
\hline & & $\mathrm{nl} \mathrm{min}^{-1}$ & $10^{-7} \mathrm{~cm}^{2} \mathrm{~s}^{-1}$ & $\mathrm{pmol} \mathrm{mm}^{-1} \min$ \\
\hline $\mathrm{C}$ & - & $7.42 \pm 0.65$ & $16.90 \pm 1.74$ & $964 \pm 80$ \\
\hline E1 & $\mathrm{Na}^{+}$free & $7.07 \pm 0.57$ & $12.00 \pm 1.40^{*}$ & $706 \pm 66^{*}$ \\
\hline E2 & $\begin{array}{l}\mathrm{Na}^{+} \text {free }+10^{-4} \\
\mathrm{M} \text { TCM }\end{array}$ & $6.80 \pm 0.58$ & $10.18 \pm 0.93$ & $625 \pm 52$ \\
\hline $\mathbf{R}$ & - & $7.02 \pm 0.24$ & $12.96 \pm 1.13^{*}$ & $777 \pm 58^{*}$ \\
\hline
\end{tabular}

Data are from seven tubules with length of $0.34 \pm 0.02 \mathrm{~mm}$.

${ }^{*} P<0.01$ as compared to the values of preceding periods.

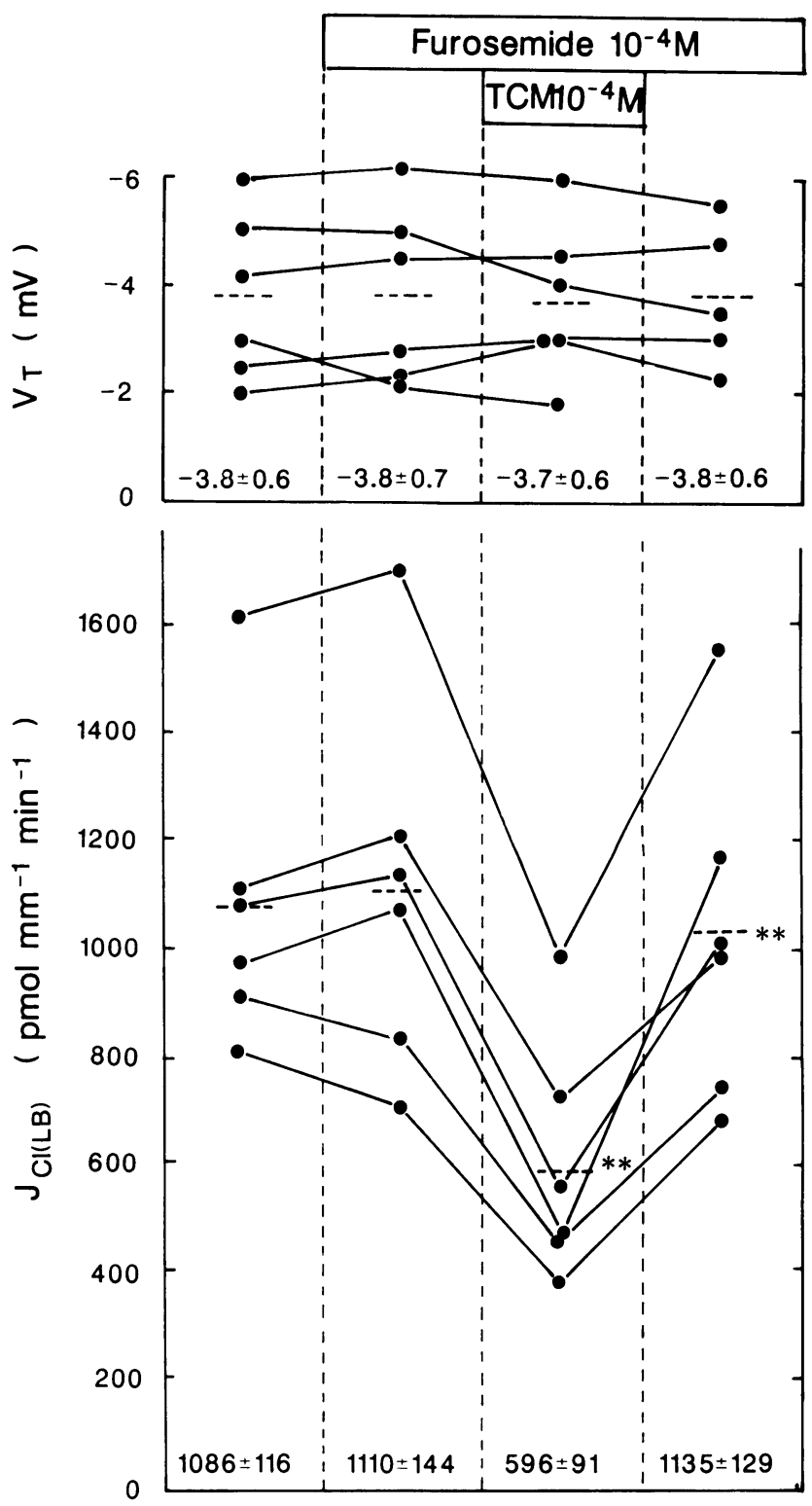

Figure 6. Effects of $10^{-4} \mathrm{M}$ furosemide and $10^{-4} \mathrm{M} \mathrm{TCM}$ on $\mathrm{V}_{\mathrm{T}}$ and $J_{\mathrm{Cl}(\mathrm{LB})}$. Tubular length was $0.39 \pm 0.03 \mathrm{~mm}$. Perfusion rates in each period were $8.03 \pm 0.37,8.25 \pm 1.04,7.11 \pm 0.64$, and $8.22 \pm 0.42 \mathrm{nl} /$ min. Values are means SE. ${ }^{* *} P<0.01$ as compared with the preceding values.

To provide further evidence for this notion, we observed the effect of high concentration of amiloride on $\mathrm{Cl}^{-}$flux. Amiloride was assumed to inhibit $\mathrm{Na}^{+} / \mathrm{H}^{+}$antiporter at $10^{-3} \mathrm{M}$. If the parallel antiport of $\mathrm{Na}^{+} / \mathrm{H}^{+}$and $\mathrm{Cl}^{-} / \mathrm{HCO}_{3}^{-}$is operating, amiloride at this concentration will cause $J_{\mathrm{Cl}(\mathrm{LB})}$ to decrease. This expectation was confirmed by the experimental data shown in Fig. 9. In the presence of $10^{-3} \mathrm{M}$ amiloride, $10^{-4} \mathrm{M}$

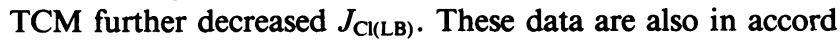
with the view that the TCM-inhibitable $\mathrm{Cl}^{-}$transport is distinct from the parallel antiport of $\mathrm{Na}^{+} / \mathrm{H}^{+}$and $\mathrm{Cl}^{-} / \mathrm{HCO}_{3}^{-}$.

\section{Discussion}

Site of action of thiazide diuretics. At present time, it is generally believed that the major site of action of thiazides is the 

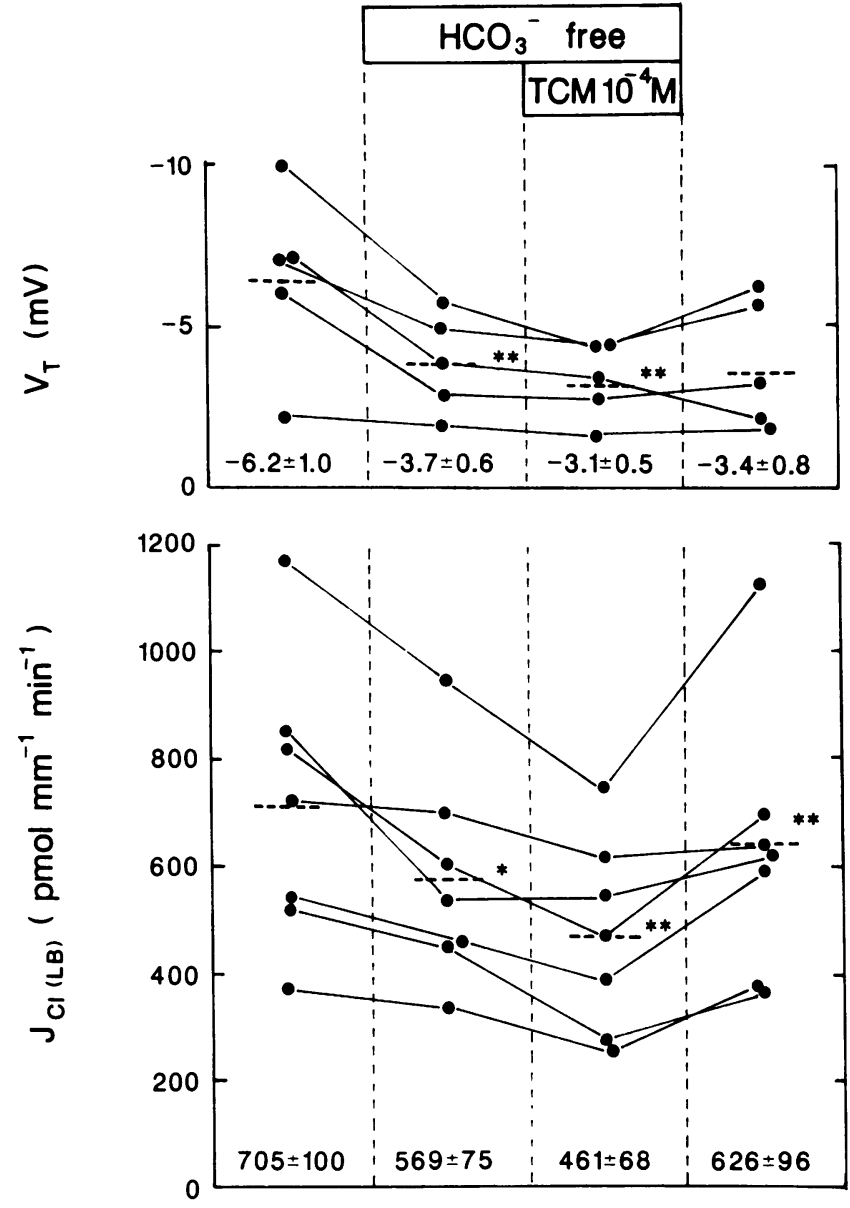

Figure 7. Effects of elimination of bicarbonate and addition of $10^{-4}$ M TCM on transmural voltage $\left(V_{\mathrm{T}}\right)$ and lumen-to-bath $\mathrm{Cl}^{-}$flux $\left(J_{\mathrm{Cl}(\mathrm{LB})}\right)$ in the CNT values are means $\pm \mathrm{SE}$. Tubular length was $0.34 \pm 0.02 \mathrm{~mm}$. Perfusion rates in each period were $7.42 \pm 0.65$, $7.07 \pm 0.59,6.80 \pm 0.58$, and $7.02 \pm 0.24 \mathrm{nl} / \mathrm{min}$, respectively. ${ }^{*} P$ $<0.05,{ }^{* *} P<0.01$ as compared with the preceding values.

distal convoluted tubule. This notion is based on the data derived from both osmolar clearance and micropuncture studies. The observations that thiazides inhibit free water clearance without affecting free water reabsorption (1-3) support the view that the drugs inhibit solute transport in the cortical diluting segments. Theoretically, the cortical diluting segments include all the water impermeable nephron segments located distally to the medullary thick ascending limb.

More direct evidence with regard to the site of action of thiazides has been provided by micropuncture studies (4-10). Ullrich et al. (4), using split oil-droplet technique, found that chlorothiazide inhibits sodium transport in both proximal and distal convolutions. Although early free-flow micropuncture studies in the $\operatorname{dog}(25)$ and rat (26) have failed to demonstrate the action of thiazides on the proximal tubule, a number of subsequent studies have confirmed that thiazides inhibit sodium chloride reabsorption in this segment $(6,25,27,28)$. However, the inhibition by thiazides of sodium chloride reabsorption in the proximal tubule may not contribute in major way to the increase in urinary excretion of sodium chloride, because the increase in distal delivery of sodium chloride is compensated by the increased reabsorption of sodium chloride in the loop of Henle (6). Free-flow micropuncture $(6,9)$ and in

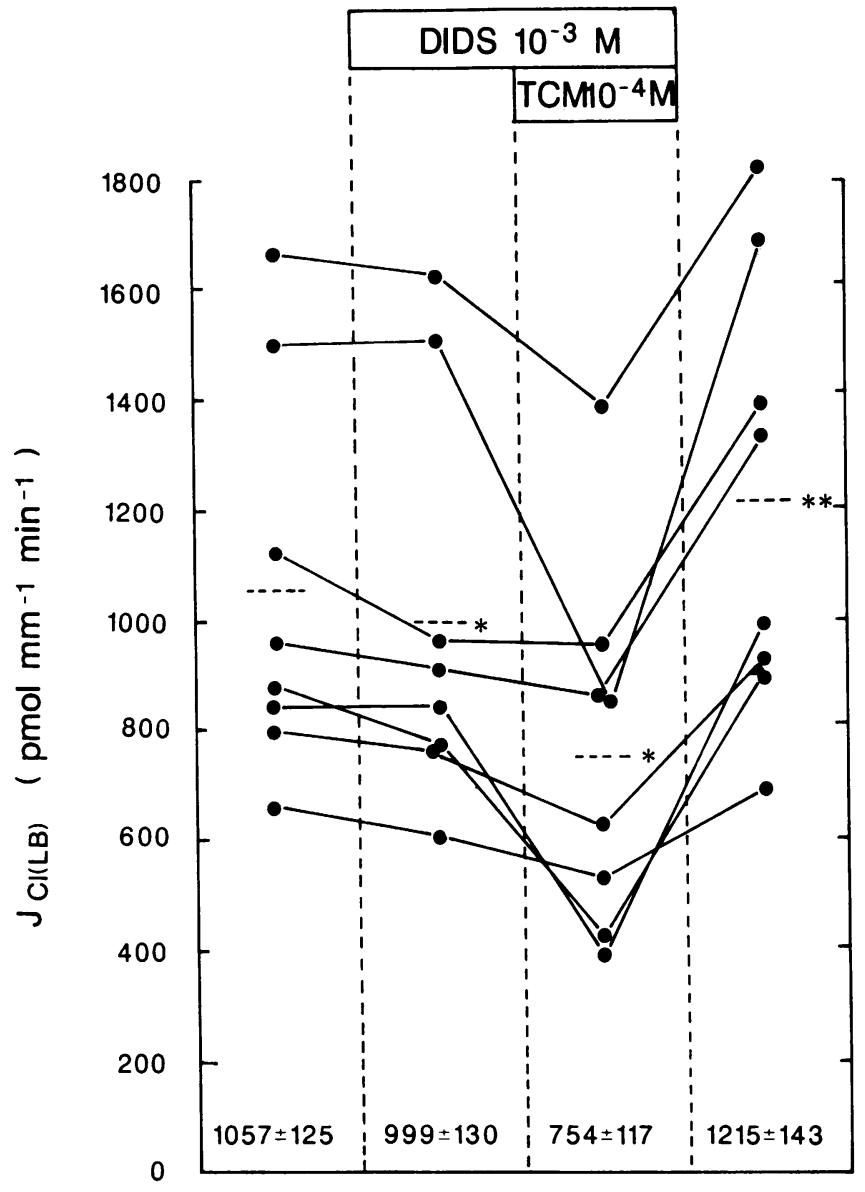

Figure 8. Effects of $10^{-3} \mathrm{M}$ DIDS and $10^{-4} \mathrm{M}$ TCM on $J_{\mathrm{C}(\mathrm{LB})}$ in the CNT. Values are means \pm SE. Tubular length was $0.34 \pm 0.01 \mathrm{~mm}$. Perfusion rates in each period were $9.09 \pm 0.47,7.66 \pm 0.35$, $6.87 \pm 0.19$, and $8.27 \pm 0.26 \mathrm{nl} / \mathrm{min}$, respectively. ${ }^{*} P<0.05,{ }^{* *} P$ $<0.01$ as compared to the preceding values.

vivo microperfusion study $(7,8,10)$ in the rat clearly demonstrated that thiazides inhibit sodium chloride transport in the distal tubule.

Although the cortical thick ascending limb has characteristics of the cortical diluting segments, Schlatter et al. (29) reported that thiazide did not affect $\mathrm{Cl}^{-}$transport in this segment isolated from rabbits. The distal tubule as defined by micropuncture studies is a heterogeneous segment composed of several morphologically as well as functionally distinct segments, including the DCT, the CNT, and the CCD (11-14). In vitro microperfusion of isolated nephron segments is expected to provide a good mean to identify the exact site of action of thiazides in the distal nephron segments. We have chosen the rabbit kidney to examine this issue for the following three reasons. First the isolation of individual distal nephron segments from the kidney without enzymatic treatment is technically feasible only in the rabbit (13-17). Second, informations on the functional heterogeneity are available in the distal nephron segments of this species $(13-17,22)$. Finally, the morphological transition from one segment to another is so abrupt in the rabbit kidney that we may obtain a pure segment without contamination of other segments $(11,12)$. The results of the present study clearly indicate that TCM inhibits sodium 


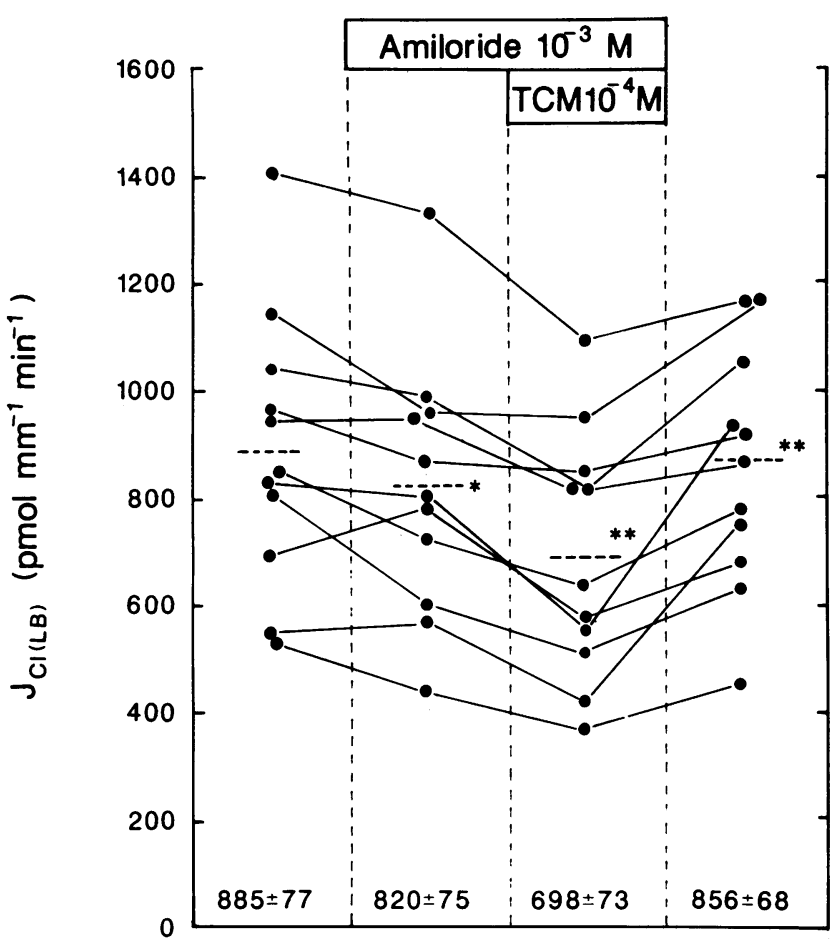

Figure 9. Effects of $10^{-3} \mathrm{M}$ amiloride on $J_{\mathrm{Cl}(\mathrm{LB})}$ in the CNT. Values are means $\pm S E$. Tubular length was $0.42 \pm 0.04 \mathrm{~mm}$. Perfusion rates in each periods were $9.24 \pm 0.46,9.04 \pm 0.47,8.60 \pm 0.43$, and $9.54 \pm 0.47 \mathrm{nl} / \mathrm{min} .{ }^{*} P<0.05,{ }^{* *} P<0.01$ as compared to the preceding values.

chloride transport only in the CNT but neither in the DCT nor in the CCD. The absence of the effect of thiazides on the CCD is in good agreement with the observation of Tago et al. (30). Our observations are apparently contradictory to those of Costanzo (9) and Ellison et al. (10), who reported that in the rat chlorothiazide inhibited $\mathrm{NaCl}$ transport only in the earliest distal nephron segment but not in late distal segments, which presumably included both the CNT and initial collecting duct. Although we do not know how to explain this discrepancy, species difference in the morphology of the distal nephron segments between rats and rabbits may be, at least in part, responsible for this discrepancy. It should be noted that in the rat distal nephron the transition from one segment to the other is gradual and both intercalated cells and connecting tubule cells are intermingled in early distal portion (12).

Because of the discrepancies between rats and rabbits with regard to the target segment of thiazide action, we have tried to provide more information on the characteristics of the rabbit DCT (Figs. 2 and 3). We confirmed that the DCT has an amiloride sensitive $\mathrm{Na}^{+}$transport system in the luminal membrane as does the CNT. The luminal membrane of the DCT may lack a $\mathrm{Na}^{+}-\mathrm{K}^{+}-2 \mathrm{Cl}^{-}$cotransport system that is supposed to be sensitive to furosemide. Even combined administration of furosemide and TCM did not affect $\mathrm{Cl}^{-}$transport of the DCT. Thus the segment of DCT that we identified is clearly distinct from either the thick ascending limb or the CNT.

Kaissling and Kriz (11) have reported that each distal nephron segment in the rabbit kidney consists of different types of epithelia: the DCT consists of a single population of the distal convoluted tubule cell; the CNT contains the connecting tubule cell and the intercalated cell, and the CCD is composed of the principal cell and the intercalated cell. On the basis of this morphological distinction of epithelial constituent in each segment, we can determine which type of epithelia is the target of the action of thiazides. The DCT cell is clearly excluded, since the segment of DCT consist of single cell population and TCM was without effect. If the intercalated cell were to be the target, thiazides could have inhibited sodium chloride transport in the CCD as well. Thus, it is most likely that the CNT cell is the target of thiazides. It is of interest to note that in the Amphiuma late distal tubule hydrochlorothiazide acts on one of two cell types having conductance to $\mathrm{K}^{+}$and $\mathrm{Cl}^{-}$in the basolateral membrane (31). However, it is unknown at present time whether this type of cell corresponds to the CNT cell in the mammalian kidney.

Mechanism of action of thiazide diuretics. Although it is known that thiazides have a property of carbonic anhydrase inhibitor, the diuretic potency of thiazides is not always in parallel with the potency of carbonic anhydrase inhibition (32). By using free-flow micropuncture in the rat, Kunau et al. (6) compared the effect of chlorothiazide with that of benzolamide, an inhibitor of carbonic anhydrase. They demonstrated that benzolamide did not show any effect on chloride transport in the distal tubule although it inhibited chloride transport in the proximal tubule as did chlorothiazide. Thus, carbonic anhydrase inhibition if not responsible for the mechanism of diuretic action of thiazides. Our observation that TCM inhibits $\mathrm{Cl}^{-}$transport in the absence of bicarbonate supports this view.

Costanzo and Windhager (7) observed the effect of chlorothiazide on sodium absorption in the superficial distal tubule of the rat kidney perfused in vitro with a sodium chloridecontaining and bicarbonate-free solution. They demonstrated that the drug inhibited sodium transport when it was applied in the lumen. This inhibitory effect was associated with a decrease in specific transepithelial resistance without any change in transepithelial voltage. This observation is in accord with the view that thiazides inhibit an electroneutral transport mechanism. Velàzquez et al. (33) reported that in the rat distal tubule there is a sodium-dependent chloride transport mechanism. More recently, Wright and his associates $(9,10)$ demonstrated that thiazides inhibit this process. The observation in the present study that TCM did not inhibit $\mathrm{Cl}^{-}$flux in the absence of $\mathrm{Na}^{+}$supports the view that the drug affects sodium-dependent chloride transport in the CNT.

In the present study, we have analyzed the thiazide inhibitable sodium-dependent chloride transport more in detail in the CNT. Neutral sodium-dependent chloride transport includes at least three different categories; i.e., $\mathrm{Na}^{+}-\mathrm{Cl}^{-}$cotransport, $\mathrm{Na}^{+}-\mathrm{K}^{+}-2 \mathrm{Cl}^{-}$cotransport, and parallel antiport of $\mathrm{Na}^{+} / \mathrm{H}^{+}$and $\mathrm{Cl}^{-} / \mathrm{HCO}_{3}^{-}$. We observed in the CNT that furosemide did not affect chloride transport and that TCM inhibited chloride flux in the presence of furosemide. These observations exclude the possible contribution of $\mathrm{Na}^{+}-\mathrm{K}^{+}-2 \mathrm{Cl}^{-} \mathrm{CO}-$ transport system in the action of TCM.

However, it is somewhat difficult to reconcile our data to those obtained in the rat distal tubule $(8,9,28,33,34)$. Using free flow micropuncture technique in the rat, Duarte et al. (34) found that during intravenous administration of furosemide sodium reabsorption in the distal tubule was not increased, even though the sodium concentration in the distal fluid was increased. It is possible that under these experimental conditions furosemide prevented the increase in sodium reabsorp- 
tion that would be expected to occur in response to the increase in luminal sodium concentration. Using in vivo microperfusion of the rat distal tubule, Velàzquez et al. (33) demonstrated that furosemide decreased sodium and chloride transport without affecting transmural voltage. One possible explanation for the discrepancy with our observation in regard to furosemide action could be that furosemide acts on the DCT but not on the CNT. But this possibility is unlikely in view of the more recent observation of Velàzquez and Wright (9). They reported that chlorothiazide caused a more profound inhibition of sodium chloride transport in the rat distal tubule than did furosemide. When $10^{-3} \mathrm{M}$ chlorothiazide was added to perfusion fluid containing furosemide and amiloride, additional inhibition of both sodium and chloride absorption was noted. On the other hand, addition of $10^{-3} \mathrm{M}$ furosemide to perfusate containing chlorothiazide did not cause additional reduction of sodium or chloride transport. These observations are consistent with the view that both chlorothiazide and furosemide act on the site with furosemide having a lower efficacy. Since Velàzquez and Wright (9) demonstrated that bumetanide, a more potent loop diuretic, did not inhibit sodium and chloride absorption in the rat distal tubule, the effect of furosemide on sodium chloride transport in this segment may not be mediated by the action on $\mathrm{Na}^{+}-\mathrm{K}^{+}-2 \mathrm{Cl}^{-}$cotransporter. Since Stokes (35) also reported that in the urinary bladder of flounder furosemide at $10^{-3} \mathrm{M}$ decreased $\mathrm{NaCl}$ fluxes, whereas bumetanide was jneffective, it is highly possible that such peculiar action of furosemide is different among species and is lacking in the rabbit.

Parallel antiport of $\mathrm{Na}^{+} / \mathrm{H}^{+}$and $\mathrm{Cl}^{-} / \mathrm{HCO}_{3}^{-}$has been shown to exist in various biological membranes (36-41). We assessed whether this type of parallel antiport exists in the CNT and whether TCM affects this system. The results of three different approaches lead us to speculate that there is parallel antiport of $\mathrm{Na}^{+} / \mathrm{H}^{+}$and $\mathrm{Cl}^{-} / \mathrm{HCO}_{3}^{-}$in the CNT but that this is not a major target of thiazide action. When the $\mathrm{Na}^{+} / \mathrm{H}^{+}$antiport system was inhibited by administration of $10^{-3} \mathrm{M}$ amiloride, the lumen-to-bath $\mathrm{Cl}^{-}$flux was slightly but significantly decreased. This would suggest that the $\mathrm{Cl}^{-}$flux is somehow related with the $\mathrm{Na}^{+} / \mathrm{H}^{+}$antiport, although we can not rule out the possibility that a high concentration of amiloride might have caused a nonspecific inhibition of $\mathrm{Cl}^{-}$transport. The possible existence of $\mathrm{Cl}^{-} / \mathrm{HCO}_{3}^{-}$or $\mathrm{Cl}^{-} / \mathrm{OH}^{-}$antiport is supported by the observations that the $\mathrm{Cl}^{-}$flux was slightly but significantly decreased by either administration of DIDS or elimination of bicarbonate. These observations are consistent with the view that the parallel antiport of $\mathrm{Na}^{+} / \mathrm{H}^{+}$and $\mathrm{Cl}^{-} / \mathrm{HCO}_{3}^{-}$might be operating in the $\mathrm{CNT}$. However, the component of $\mathrm{Cl}^{-}$transported via this system may be very small. Since TCM exhibited remarkable inhibitory effects on $\mathrm{Cl}^{-}$flux under all conditions where $10^{-3} \mathrm{M}$ amiloride or $10^{-4} \mathrm{M}$ DIDS was present in the lumen or bicarbonate was eliminated, the target of TCM action is distinct from the parallel antiport of $\mathrm{Na}^{+} / \mathrm{H}^{+}$and $\mathrm{Cl}^{-} / \mathrm{HCO}_{3}^{-}$. Although the $\mathrm{CNT}$ consists of at least two different types of epithelia, we cannot exclude the possibility that both $\mathrm{Na}^{+}-\mathrm{Cl}^{-}$cotransport and parallel antiport system coexist in the one type of cell as observed in the rabbit gall bladder (41). However, in view of the fact that bicarbonate secretion occurs in the CCD (42-45), it is more likely that the parallel antiport of $\mathrm{Na}^{+} / \mathrm{H}^{+}$and $\mathrm{Cl}^{-} / \mathrm{HCO}_{3}^{-}$exists in the intercalated cell in the CNT. Our observation that TCM inhibited net $\mathrm{Cl}^{-}$flux only by $31 \%$ (Table $\mathrm{V}$ ) is in accord with the hypothesis that there are $\mathrm{Cl}^{-}$transport mechanisms other than $\mathrm{Na}^{+}-\mathrm{Cl}^{-}$cotransport. It is unknown whether $\mathrm{Cl}^{-} / \mathrm{HCO}_{3}^{-}$exchanger entirely accounts for this component.

Late distal tubule of amphibian kidney is regarded to be comparable to the distal tubule of mammalian kidney $(31,46)$. Hansen, Schilling and Wiederholt (46) reported that in the late distal tubule of Amphiuma $10^{-4} \mathrm{M}$ chlorothiazide added to the lumen caused hyperpolarization of basolateral membrane voltage by $-23 \mathrm{mV}$. More recently, Stanton (31) confirmed this observation in type II cells of the late distal tubule of the Amphiuma kidney. Although he suggested the existence of parallel antiport of $\mathrm{Na}^{+} / \mathrm{H}^{+}$and $\mathrm{Cl}^{-} / \mathrm{HCO}_{3}^{-}$, coexistence of simple $\mathrm{Na}^{+}-\mathrm{Cl}^{-}$symport cannot be ruled out.

By excluding other possible mechanisms that explain the $\mathrm{Na}^{+}$dependent electroneutral $\mathrm{Cl}^{-}$transport, we reached the conclusion that a "simple" $\mathrm{Na}^{+}-\mathrm{Cl}^{-}$cotransport system exists in the CNT and that this is the major target of the action of thiazide diuretics. A similar conclusion was made by Stokes et al. (45) based on the studies in the urinary bladder of winter flounder. They demonstrated in this preparation a $\mathrm{Na}^{+}$-dependent $\mathrm{Cl}^{-}$transport system that is not inhibited by high dose of amiloride or DIDS and is little affected by loop diuretics. Although it has been reported in the toad or frog urinary bladder $(47,48)$ that thiazide inhibits electrogenic $\mathrm{Na}^{+}$absorption, this is clearly not the case in the mammalian CNT.

In summary, there are three distinct mechanisms of $\mathrm{Na}^{+}$ transport in the luminal membrane of the rabbit CNT: $(a)$ amiloride-dependent $\mathrm{Na}^{+}$conductance, $(b)$ parallel antiport of $\mathrm{Na}^{+} / \mathrm{H}^{+}$and $\mathrm{Cl}^{-} / \mathrm{HCO}_{3}^{-}$, and (c) simple $\mathrm{Na}^{+}-\mathrm{Cl}^{-}$cotransport. The inhibition of $\mathrm{Na}^{+}-\mathrm{Cl}^{-}$cotransport is the major mechanism involved in the diuretic action of thiazides.

\section{Acknowledgments}

We would like to express our thanks to Mrs. Yayoi Ueshima for preparing this manuscript.

\section{References}

1. Early, L. E., M. Kahn, and J. Orloff. 1961. The effects of infusions of chlorothiazide on urinary dilution and concentration in the dog. J. Clin. Invest. 40:857-866.

2. Suki, W., F. C. Rector, and D. W. Seldin. 1965. The site of action of furosemide and other sulfonamide diuretics in the dog. J. Clin. Invest. 44:1458-1469.

3. Seldin, D. W., G. Eknoyan, W. N. Suki, and F. C. Rector, Jr. 1966. Localization of diuretic action from the pattern of water and electrolyte excretion. Ann. NY Acad. Sci. 139:328-343.

4. Ullrich, K. G., K. Baumann, K. Loeschke, G. Rumrich, and H. Stolte. 1966. Micropuncture experiments with saluretic sulfonamides. Ann. NY Acad. Sci. 139:416-423.

5. Clapp, J. R., and R. R. Robinson. 1968. Distal site of action of diuretic drug in the dog nephron. Am. J. Physiol. 215:228-235.

6. Kunau, R. T. Jr., D. R. Weller, and H. L. Webb. 1975. Clarification of the site of action of chlorothiazide in the rat nephron. J. Clin. Invest. 56:401-407.

7. Costanzo, L. S., and E. E. Windhager. 1978. Calcium and sodium transport by the distal convoluted tubule of the rat. Am. J. Physiol. 235:F492-F506.

8. Costanzo, L. S. 1985. Localization of diuretic action in microperfused rat distal tubules: $\mathrm{Ca}$ and $\mathrm{Na}$ transport. Am. J. Physiol. 248:F527-F535.

9. Velàzquez, H., and F. S. Wright. 1986. Effect of diuretic drugs on 
$\mathrm{Na}, \mathrm{Cl}$, and $\mathrm{K}$ transport by rat renal distal tubule. Am. J. Physiol. 250:F1013-F1023.

10. Ellison, D. H., H. Velàzquez, and F. S. Wright. 1987. Thiazide-sensitive sodium chloride cotransport in early distal tubule. Am. J. Physiol. In press.

11. Kaissling, B., and W. Kriz. 1979. Structural analysis of the rabbit kidney. Adv. Anat. Embryol. Cell. Biol. 56:1-123.

12. Kaissling, B. 1982. Structural aspects of adaptive changes in renal electrolyte excretion. Am. J. Physiol. 243:F211-F226.

13. Imai, M. 1979. The connecting tubule: a functional subdivision of the rabbit distal nephron segments. Kidney Int. 15:346-356.

14. Imai, M., and R. Nakamura. 1982. Function of distal convoluted and connecting tubules studied by isolated nephron fragments. Kidney Int. 22:465-472.

15. Imai, M. 1981. Effects of parathyroid hormone and $N^{6}, O^{21}$-dibutyryl cyclic AMP on $\mathrm{Ca}^{2+}$ transport across the rabbit distal nephron segments perfused in vitro. Pfluegers Arch. 390:145-151.

16. Shareghi, G. R., and L. C. Stoner. 1978. Calcium transport across segments of the rabbit distal nephron. Am. J. Physiol. 235:F367-F375.

17. Almedia, A. J., and M. B. Burg. 1982. Sodium transport in the rabbit connecting tubule. Am. J. Physiol. 243:F330-F334.

18. Burg, M., J. Grantham, M. Abramow, and J. Orloff. 1966. Preparation and study of fragments of single rabbit nephron. Am. J. Physiol. 210:1293-1298.

19. Nagineni, C. N., P. J. Leveille, D. B. N. Lee, and N. Yanagawa. 1984. Isolation of cells from rabbit renal proximal tubules by using a hyperosmolar intracellular-like solution. Biochem. J. 223:353-358.

20. Pirie, S. C., and D. J. Potts. 1985. Application of cold flush preservation to in vitro microperfusion studies of kidney tubules. Kidney Int. 28:982-984.

21. Pirie, S. C., and D. J. Potts. 1986. A comparison of the relative effectiveness of three transplant preservation fluids upon integrity and function of rabbit proximal convoluted tubules perfused in vitro. Clin. Sci. 70:443-452.

22. Gross, J. B., M. Imai, and J. P. Kokko. 1975. A functional comparison of the cortical collecting tubule and the distal convoluted tubule. J. Clin. Invest. 55:1284-1294.

23. Grantham, J. J., and M. B. Burg. 1966. Effect of vasopressin and cyclic AMP on permeability of isolated collecting tubules. Am. J. Physiol. 221:255-259.

24. Imai, M., and J. P. Kokko. 1974. Sodium chloride urea and water transport in the thin ascending limb of Henle. Generation of osmotic gradients by possive diffusion of solutes. J. Clin. Invest. 53:393-402.

25. Dirks, J. H., W. J. Cirksena, and R. W. Berliner. 1966. Micropuncture study of the effects of various diuretics on sodium reabsorption by the proximal tubules of the dogs. J. Clin. Invest. 45:1875-1885.

26. Meng, K. 1967. Mikropunktionsuntersuchungen über die saluretische Wirkung von Hydrochlorothiazid, Acetazolamid und Furosemid. Arch. Pharmakol. Exp. Ther. 257:355-371.

27. Hernandez, P. C., and J. B. Puchett. 1973. Proximal tubular actions of metolazon and chlorothiazide. Am. J. Physiol. 225:954-961.

28. Edward, B. R., P. G. Baer, R. A. Sutton, and J. H. Dirks. 1973. Micropuncture study of diuretic effects on sodium and calcium reabsorption in the dog nephron. J. Clin. Invest. 52:2485-2427.

29. Schlatter, E., R. Greger, and C. Weidtke. 1983. Effect of "high ceiling" diuretics on active salt transport in the cortical thick ascending limb of Henle's loop of rabbit kidney. Correlation of chemical structure and inhibitory potency. Pfluegers Arch. 396:210-217.

30. Tago, K., V. L. Schuster, and J. B. Atokes. 1986. Regulation of chloride self exchange by cAMP in cortical collecting tubule. Am. J. Physiol. 251:F40-F48.

31. Stanton, B. 1988. Electroneutral $\mathrm{NaCl}$ transport by distal tubule: evidence for $\mathrm{Na}^{+} / \mathrm{H}^{+}-\mathrm{Cl}^{-} / \mathrm{HCO}_{3}^{-}$exchange. Am. J. Physiol. 254:F80-F86.

32. Maren, T. H. 1963. The relation between enzyme inhibition and physiological response in the carbonic anhydrase system. J. Pharmacol. Exp. Ther. 139:140-153.

33. Velàzquez, H., D. W. Good, and F. S. Wright. 1984. Mutual dependence of sodium and chloride absorption by renal distal tubule. Am. J. Physiol. 247:F904-F911.

34. Duarte, C. G., F. Chomety, and G. Giebisch. 1971. Effect of amiloride, ouabain and furosemide on distal tubular function in the rat. Am. J. Physiol. 221:632-639.

35. Stokes, J., I. Lee, and M. D'Amico. 1984. Sodium chloride absorption by the urinary bladder of the winter flounder. A thiazidesensitive, electrically neutral transport system. J. Clin. Invest. 74:7-16.

36. Murer, H., U. Hopfer, and R. Kinne. 1976. Sodium/proton antiport in brush border membrane vesicle isolated from rat small intestine. Biochem. J. 154:597-604.

37. Heintze, K., K. U. Petersen, and J. Wood. 1981. Effects of bicarbonate on fluid and electrolyte transport by guinea pig and rabbit gallbladder: Stimulation of absorption. J. Membr. Biol. 62:175-181.

38. Friedman, P. A., and T. E. Andreoli. 1982. $\mathrm{CO}_{2}$ stimulated $\mathrm{NaCl}$ absorption in the mouse renal cortical thick ascending limb of Henle. Evidence for synchronous $\mathrm{Na}^{+} / \mathrm{H}^{+}$and $\mathrm{Cl}^{-} / \mathrm{HCO}_{3}^{-}$exchange in apical plasma membranes. J. Gen. Physiol. 80:683-711.

39. Baerentsen, H., F. Giraldez, and T. Zeuthen. 1983. Influx mechanisms for $\mathrm{Na}^{+}$and $\mathrm{Cl}^{-}$across the brush border membrane of leaky epithelia: A model and microelectrode study. J. Membr. Biol. 75:205-218.

40. Aronson, P. S., and J. Seifter. 1984. $\mathrm{Cl}^{-}$transport via anion exchange. Fed. Proc. 43:2483-2484.

41. Cremaschi, D., G. Meyer, C. Rossetti, G. Botta, and P. Palestini. 1987. The nature of the neutral $\mathrm{Na}^{+}-\mathrm{Cl}^{-}$-coupled entry at the apical membrane of rabbit gallbladder epithelium: I. $\mathrm{Na}^{+} / \mathrm{H}^{+}, \mathrm{Cl}^{-} /$ $\mathrm{HCO}_{3}^{-}$double exchange and $\mathrm{Na}^{+}-\mathrm{Cl}^{-}$symport. J. Membr. Biol. 95:209-218.

42. Star, R. A., M. B. Burg, and M. A. Knepper. 1985. Bicarbonate secretion and chloride absorption by rabbit cortical collecting ducts. Role of chloride/bicarbonate exchange. J. Clin. Invest. 76:1123-1130.

43. Laski, M. E., D. G. Warnock, and F. C. Rector, Jr. 1983. Effects of chloride gradients on total $\mathrm{CO}_{2}$ flux in the rabbit cortical collecting tubule. Am. J. Physiol. 244:F289-F296.

44. Garcia-Austt, J., D. W. Good, M. B. Burg, and M. A. Knepper. 1985. Deoxycorticosterone-stimulated bicarbonate secretion in rabbit cortical collecting ducts: effects of luminal chloride removal and in vivo acid loading. Am. J. Physiol. 249:F205-F212.

45. Schuster, V. L. 1985. Cyclic adenosine monophosphate-stimulated bicarbonate secretion in rabbit cortical collecting tubules. J. Clin. Invest. 75:2056-2064.

46. Hansen, L. L., A. R. Schilling, and M. Wiederholt. 1981. Effect of calcium, furosemide and chlorothiazide on net volume reabsorption and basolateral membrane potential of the distal tubule. Pfluegers Arch. 389:121-126.

47. Schneiders, J. R., and J. H. Ludens. 1980. Comparison of effects of standard diuretics and endanone in isolated toad cornea and bladder. Am. J. Physiol. 238:R70-R75.

48. Marumo, F., T. Mishina, and H. Shimada. 1982. Effects of dioxide and hydrochlorothiazide on water permeability and sodium transport in the frog bladder. Pharmacology. 24:175-180. 